\title{
Reliability of a Smartphone Goniometric Application in the Measurement of Hip Range of Motion Among Experienced and Novice Clinicians
}

\author{
Enda Whyte, Tiarnán Ó Doinn, Miriam Downey, and Siobhán O’Connor
}

\begin{abstract}
Context: Deficits in the hip range of motion are associated with hip and groin injuries. Accurate and reliable goniometric measurements are important in identifying those at risk of injury and determining the efficacy of treatment interventions. Smartphone goniometric applications are regularly used to assess joint ranges of motion; however, there is limited knowledge on the reliability of this method in relation to the hip, particularly between clinicians with different levels of experience. Objective: To determine the intratester and intertester reliability of a smartphone clinometer application for the assessment of hip goniometric measurements in healthy volunteers by an experienced and novice clinician. Design: Reliability study. Setting: University Athletic Therapy facility. Participants: Physically active, university students. Main Outcome Measures: The study determined the intra- and intertester (experienced vs novice clinician) reliability of goniometric measurements of the hip joint (modified Thomas test and seated hip internal and external rotation) using a smartphone goniometric application. Intraclass correlation coefficients (ICCs), standard error of measurement, and minimal detectable change at a $95 \%$ confidence interval were used to assess reliability. Results: Goniometric measurements demonstrated good to excellent relative intratester reliability for the modified Thomas test $(\mathrm{ICC}=.94)$, external rotation $(\mathrm{ICC}=.93-.95)$, and internal rotation $(\mathrm{ICC}=.80-.81)$. Intertester reliability for expert and novice clinicians was also excellent for the modified Thomas test $(\mathrm{ICC}=.98)$, external rotation $(\mathrm{ICC}=.95)$, and internal rotation ( $\mathrm{ICC}=.92)$. Intratester and intertester standard error of measurement and minimal detectable change at $95 \%$ confidence interval values were similar for both testers and ranged from $1.9^{\circ}$ to $3.6^{\circ}$ and $5^{\circ}$ to $10.1^{\circ}$ and from $1.1^{\circ}$ to $2.3^{\circ}$ and $2.9^{\circ}$ to $6.5^{\circ}$, respectively. Conclusion: Smartphone-based goniometric measurements of hip range of motion have high intratester and intertester reliability for novice and expert clinicians. It may be a useful, simple, and inexpensive resource for clinicians.
\end{abstract}

Keywords: clinical assessment, joint angle, mobile phone

Injuries to the hip and groin frequently occur in multidirectional field sports. Deficits in hip extension are proposed to be a factor in the development of chronic groin pain, ${ }^{1}$ while reduced hip rotation is associated with hip and groin pain. ${ }^{2}$ Therefore, it is essential that measurement techniques are reliable and practical for a range of clinicians.

Accelerometer-based smartphone goniometric applications (SGA) have become an increasingly popular and valid goniometric tool. ${ }^{3}$ Although the intratester reliability of SGA of the hip range of motion (ROM) has been reported in one study only, ${ }^{3}$ the intratester reliability of hip extension and the intertester reliability of expert and novice testers have not been reported. Studies that have identified reduced hip ROM as a risk factor for hip and groin injuries using traditional goniometric methods have differences that exceed the standard error of measurement (SEM) but not the minimal detectable change (MDC), suggesting that these techniques are not appropriate for screening athletes for future hip and groin injuries. ${ }^{2}$ Therefore, this study aims to determine the intratester and intertester reliability of SGA measurements of hip ROM among experienced and novice clinicians and to

Whyte, Doinn, Downey, and O' Connor are with the Department of Athletic Therapy and Training, School of Health and Human Performance, Dublin City University, Dublin 9, Ireland. Doinn is also with the Department of Trauma and Orthopaedic Surgery, Tallaght University Hospital, Dublin, Ireland. Whyte (enda. whyte@dcu.ie) is corresponding author. report the MDC and SEM of SGA measurements of hip ROM measurements.

\section{Materials and Methods}

A minimum sample of 15 participants was required for observing minimum reliability of 0.6 by 2 raters with an alpha value of .05 and a minimum power of $80 \%{ }^{4}$ Therefore, a convenience sample of 17 young healthy males (19.9 [1.7] y, 180.7 [4.6] cm, 79.4 [3.7] $\mathrm{kg}$ ) were recruited from university Gaelic football teams. The inclusion criteria were to be aged 18-25 years, pain-free, with no significant lower limb injury in the 2 months prior to participation. All participants completed written informed consent, and ethical approval was granted by the Dublin City University Research Ethics Committee.

All measures were obtained bilaterally by an experienced ( $>30$ y clinical experience) and novice $(<1$ y clinical experience) certified athletic therapist. The testing order was randomized, and testers were blinded to all previous measurements. There was a minimum of 30 minutes between each of the retest measurements. The measurements were obtained using a smartphone (Samsung Galaxy S5, Suwon, Republic of Korea; running Android version 5.0) running a "Clinometer" application (plaincode app development and tech blog, Stephanskirchen, Germany), which is freely downloadable. Hip ROM measures consisted of the modified Thomas test to measure hip extension, and seated hip internal rotation and external 
rotation. An average of 3 was recorded for each goniometric measurement, each taking approximately 1 minute.

\section{The Modified Thomas Test}

A baseline measurement was taken with the participant sitting on a firm, horizontal plinth with both thighs fully supported and their feet elevated off the floor (Figure 1). The longest edge of the smartphone was placed in the midline of the thigh, $5 \mathrm{~cm}$ proximal to the patella. Second, the participant repositioned themselves to the edge of the plinth so that the hip to be tested was free to move into extension. Both of the participant's hips were passively flexed, and then the test limb was allowed to passively extend. The tester then adjusted the degree of hip flexion of the nontest limb to maintain the pelvis and lumbar spine in a neutral position, and the goniometric measurement was rerecorded. The range of hip extension was calculated by subtracting the baseline measurement from the second measurement angle.

\section{Hip Rotation}

Hip internal and external rotation ROM was obtained with participants seated upright on a firm plinth, with their feet elevated off the floor and arms across their chest (Figure 1). The participant's leg to be assessed was passively internally and externally rotated to encourage neutral rotation and abduction/ adduction. A baseline measurement was recorded by placing the longest edge of the smartphone $5 \mathrm{~cm}$ proximal to the lateral malleolus. For both internal and external rotation measurements (Figure 1), the hip was passively rotated until the tester felt a firm end feel or until just before compensatory movement of the pelvis or hip was produced, at which time, the measurement was recorded. The baseline measurement was then subtracted from the second measurement to give a measure of hip internal and external rotation ROM.

\section{Analysis}

The mean and SDs were calculated for all goniometric measurements. Statistical analysis was carried out using SPSS software (version 24; SPSS Inc, Chicago, IL). The data were normal, so paired $t$ tests were used to assess for any systematic intertester bias. Intraclass correlation coefficients (ICC 2.1) with corresponding 95\% CIs determined the intratester and intertester repeatability. Reliability was considered poor for ICC $<.40$, fair for ICC $=.40$ to .59 , good for $\mathrm{ICC}=.60$ to .74 , and excellent for $\mathrm{ICC}=.75$ to $1.0 .^{5}$

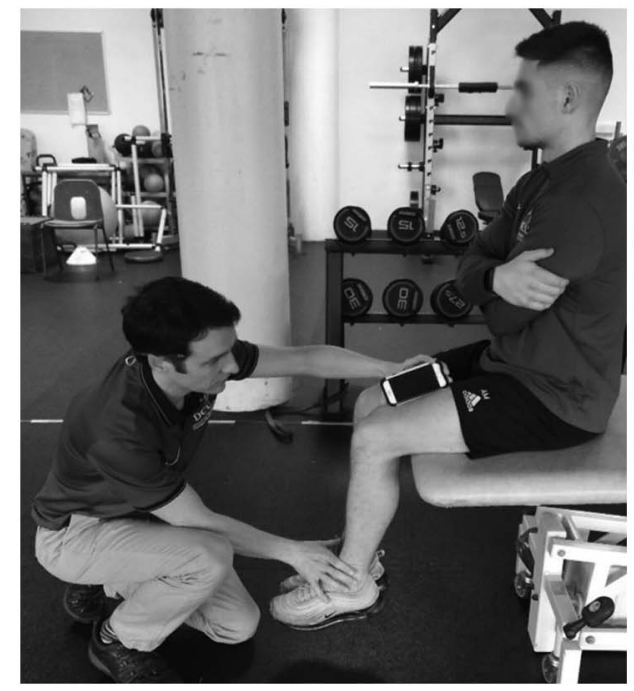

A

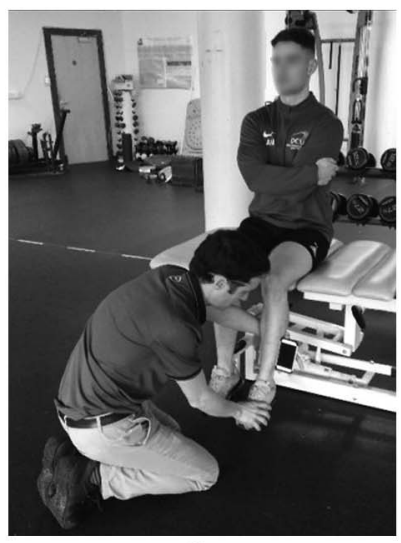

C

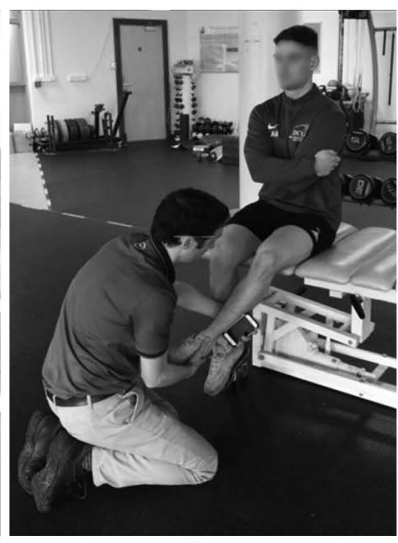

D

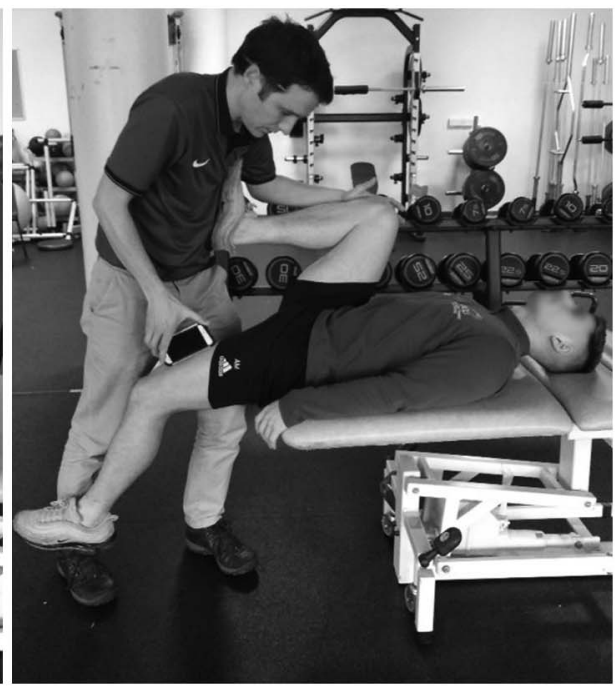

B

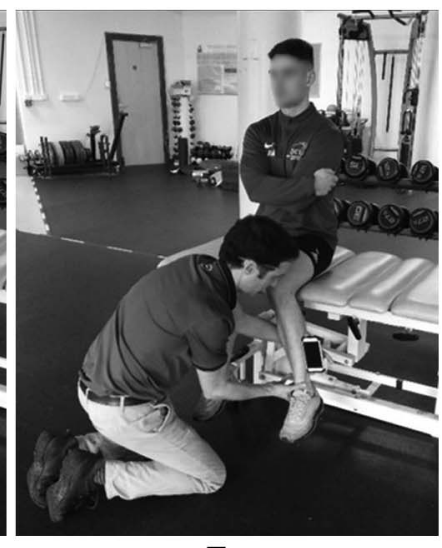

$E$

Figure 1 - Measurement of hip range of motion: (A) starting position, (B) end position for modified Thomas test, (C) starting position for hip rotation, (D) end position for hip external rotation, and (E) end position for hip internal rotation. 
Table 1 Intratester Reliability of Hip Goniometric Measurements Using a Smartphone Application

\begin{tabular}{|c|c|c|c|c|c|c|c|c|c|c|}
\hline \multirow[b]{2}{*}{ Measure } & \multicolumn{2}{|c|}{ ICC (95\% Cl) } & \multicolumn{2}{|c|}{ SEM, $^{\circ}$} & \multicolumn{2}{|c|}{ SEM, \% } & \multicolumn{2}{|c|}{$\mathrm{MDC}_{95},{ }^{\circ}$} & \multicolumn{2}{|c|}{$\mathrm{MDC}_{95}, \%$} \\
\hline & Expert & Novice & Expert & Novice & Expert & Novice & Expert & Novice & Expert & Novice \\
\hline Modified Thomas test, ${ }^{\circ}$ & $.94(.88-.97)$ & $.94(.87-.97)$ & 1.81 & 1.87 & 26.4 & 26.6 & 5.0 & 5.2 & 73.3 & 73.8 \\
\hline Internal rotation, ${ }^{\circ}$ & $.81(.61-.90)$ & $.80(.60-.90)$ & 3.47 & 3.64 & 18.8 & 18.4 & 9.6 & 10.1 & 52.1 & 50.9 \\
\hline External rotation, ${ }^{\circ}$ & $.95(.90-.98)$ & $.93(.86-.97)$ & 2.16 & 2.94 & 4.8 & 6.7 & 6.0 & 8.2 & 13.4 & 18.4 \\
\hline
\end{tabular}

Abbreviations: CI, confidence interval; ICC, intraclass correlation coefficient; $\mathrm{MDC}_{95}$, minimal detectable change at a 95\% CI; SEM, standard error of measurement. Significance of $P$ value set at $<.05$.

Table 2 Intertester Reliability of Hip Goniometric Measurements Using a Smartphone Application

\begin{tabular}{|c|c|c|c|c|c|c|c|c|c|}
\hline Measurement & $\begin{array}{c}\text { Expert } \\
\text { mean (SD) }\end{array}$ & $\begin{array}{c}\text { Novice } \\
\text { mean (SD) }\end{array}$ & $\begin{array}{c}\text { Difference } \\
\text { tester } 1- \\
\text { tester } 2 \\
\text { mean (SD) }\end{array}$ & $\begin{array}{c}\text { Paired } t \text { test } \\
P \text {-value }\end{array}$ & $\begin{array}{c}\text { ICC } \\
(95 \% \mathrm{Cl})\end{array}$ & SEM, ${ }^{\circ}$ & SEM, \% & $\mathrm{MDC}_{95}$ & MDC $_{95}, \%$ \\
\hline Modified Thomas test, ${ }^{\circ}$ & $7.05(7.51)$ & $7.19(7.35)$ & $-0.13(2.07)$ & ns & $.98(.97-.99)$ & 1.05 & 14.7 & 2.9 & 40.7 \\
\hline Internal rotation, ${ }^{\circ}$ & $18.44(7.87)$ & $19.78(8.16)$ & $1.35(4.35)$ & ns & $.92(.87-.95)$ & 2.27 & 11.9 & 6.3 & 32.9 \\
\hline External rotation, ${ }^{\circ}$ & $44.81(9.66)$ & 43.84 (11.27) & $0.97(4.51)$ & ns & $.95(.92-.97)$ & 2.34 & 5.3 & 6.5 & 14.6 \\
\hline
\end{tabular}

Abbreviations: CI, confidence interval; ICC, intraclass correlation coefficient; $\mathrm{MDC}_{95}$, minimal detectable change at a 95\% CI; ns, non-signficant; SEM, standard error of measurement. Significance of $P$ value set at $<.05$.

The $P$ values were considered significant at $<.05$. The SEM was calculated by multiplying the SD of the test scores by the square root of one less the reliability coefficient $\left(\mathrm{SEM}_{\mathrm{x}}=\mathrm{S}_{\mathrm{T}} \sqrt{ }\left[1-r_{\mathrm{xx}}\right]\right)$. This was also expressed as SEM\% by dividing the SEM by the average of the test and retest scores. The MDC at a 95\% CI was calculated using the formula $\mathrm{MDC}_{95}=\mathrm{SEM} \times 1.96 \times \sqrt{ } 2$. The $\mathrm{MDC}_{95}$ is also presented as the $\mathrm{MDC}_{95} \%$ by dividing the $\mathrm{MDC}_{95}$ by the average of the test and retest values.

\section{Results}

The mean angular measurements of each of the SGA measures for the intratester and intertester reliability analysis with SD, ICC (95\% $\mathrm{CI}$, SEM, and $\mathrm{MDC}_{95}$ are presented in Tables 1 and 2, respectively. The intratester reliability for all measurements demonstrated excellent ICC values for both the expert (.81-.95) and novice (.80-.94) testers and narrow 95\% CIs. In addition, the SEM showed similarly small values for both the novice $\left(1.87^{\circ}-3.64^{\circ}\right)$ and expert $\left(1.87^{\circ}-3.37^{\circ}\right)$ testers. The $\mathrm{MDC}_{95}$ intratester analysis for all measurements was similar for both the expert and novice testers. The $\mathrm{MDC}_{95}$ values for all measurements demonstrated that a change of $5.0^{\circ}$ to $8.2^{\circ}$ or greater would be needed to be $95 \%$ certain that the changes are not due to intratester variability or measurement error.

There were no significant differences $(P>.05)$ between the expert and novice testers for any goniometric measurement. The intertester reliability for all measurements was excellent, with high ICC values (.92-.98), narrow 95\% CI (0.87-0.99), and small SEM values $\left(1.05^{\circ}-2.34^{\circ}\right)$. The $\mathrm{MDC}_{95}$ intertester analysis for all measurements indicated that a change of $2.9^{\circ}$ to $6.5^{\circ}$ or greater would be needed to be $95 \%$ certain that the changes are not due to intertester variability or measurement error.

\section{Discussion}

Excellent intratester and intertester reliability for SGA measurements of hip extension and hip rotation were demonstrated for both the novice and expert clinicians. This, in conjunction with the previously demonstrated validity of SGAs for measuring hip $\mathrm{ROM},{ }^{3}$ indicates that SGA is a useful tool for clinicians to measure hip extension and rotation. The SEM for the intratester and intertester reliability ranged from $1.87^{\circ}$ to $3.64^{\circ}$ and $1.05^{\circ}$ to $2.34^{\circ}$, while the $\mathrm{MDC}_{95}$ ranged from $5.2^{\circ}$ to $10.1^{\circ}$ and $2.9^{\circ}$ to $6.5^{\circ}$, respectively. The SEM provides $68 \%$ probability that the true measurement lies within this range, whereas the MDC provides 95\% probability. These values can facilitate clinicians in making informed decisions.

The modified Thomas test procedure in the current study demonstrated excellent intratester reliability for the experts $(\mathrm{ICC}=$ .94 ) and novices $(\mathrm{ICC}=.94)$, higher than the values found using hand-held goniometers $\left(0.75^{6}\right)$. Similarly, higher intertester reliability between the experts and novices $(\mathrm{ICC}=.98)$ was found in the current study than the $0.92^{6}$ for hand-held goniometric measurements previously reported. The high reliability values in the current study may be due to the employment of a method that, at least partially, overcomes pelvic instability and inconsistencies in landmark identification, both of which have been shown to contribute to low reliability. 7,8

The procedure for the measurement of hip external rotation ROM in the current study demonstrated excellent intratester reliability for expert $(\mathrm{ICC}=.95)$ and novice $(\mathrm{ICC}=.93)$, higher than the 0.63 using an $\mathrm{SGA}^{3}$ and similar to the higher levels of intratester ICC values using hand-held goniometers $\left(\mathrm{ICC}=.92^{9,10}\right)$. In addition, the intertester reliability $(\mathrm{ICC}=.94)$ in the current study is higher than the 0.81 to $0.87^{9}$ previously reported. Therefore, hip external rotation measured using an SGA is a reliable method for both expert and novice clinicians.

Goniometric measurements of hip internal rotation demonstrated excellent intratester reliability for the experts $(\mathrm{ICC}=.81)$ and novices $(\mathrm{ICC}=.80)$ in the current study. This is similar to a previous study using an SGA, ${ }^{3}$ higher than the 0.67 to $0.71,{ }^{10}$ but slightly lower than 0.83 to $0.92^{9}$ using a hand-held goniometer. The higher reported reliability ${ }^{9}$ is likely due to the fact that another clinician assisted in the measurement, which is not always practical 
in a clinical situation. The current study demonstrated excellent intertester reliability for internal hip rotation $(\mathrm{ICC}=.92)$, higher than the 0.64 reported using a hand-held goniometer ${ }^{10}$ and similar to the .89 to .94 that also required the use of stabilization belts. ${ }^{9}$ Therefore, the measurement of hip internal rotation using an SGA is a highly reliable and practical method of assessment for expert and novice clinicians.

There are a number of limitations in the current study. First, only measures of hip extension and rotation range of motion were assessed. Second, the participants were young, physically active males, which limits the generalizability of the findings. Finally, the average of 3 trials for each goniometric measurement was analyzed, which may not always be practical in a clinical environment.

\section{Conclusion}

A smartphone clinometer application has excellent reliability for hip extension and rotation ROM assessment.

\section{Acknowledgment}

The authors declare no conflict of interest.

\section{References}

1. Ferguson M, Patricios J. What is the relationship between groin pain in athletes and femoroacetabular impingement? Br J Sports Med. 2014; 48(14):1074-1075. PubMed ID: 24970899 doi:10.1136/bjsports2014-093818

2. Tak I, Engelaar L, Gouttebarge V, et al. Is lower hip range of motion a risk factor for groin pain in athletes? A systematic review with clinical applications. Br J Sports Med. 2017;51(22):1611-1621. PubMed ID: 28432076 doi:10.1136/bjsports-2016-096619

3. Charlton PC, Mentiplay BF, Pua YH, Clark RA. Reliability and concurrent validity of a Smartphone, bubble inclinometer and motion analysis system for measurement of hip joint range of motion. $J \mathrm{Sci}$ Med Sport. 2015;18(3):262-267. PubMed ID: 24831757 doi:10. 1016/j.jsams.2014.04.008

4. Bujang MA, Baharum N. A simplified guide to determination of sample size requirements for estimating the value of intraclass correlation coefficient: a review. Arch Orofac Sci. 2017;12(1):1-11.

5. Cicchetti D, Bronen R, Spencer S, et al. Rating scales, scales of measurement, issues of reliability: resolving some critical issues for clinicians and researchers. J Nerv Ment Dis. 2006;194(8):557-564. PubMed ID: 16909062 doi:10.1097/01.nmd.0000230392.83607.c5

6. Gabbe BJ, Bennell KL, Wajswelner H, Finch CF. Reliability of common lower extremity musculoskeletal screening tests. Phys Ther Sport. 2004;5(2):90-97. doi:10.1016/S1466-853X(04)00022-7

7. Peeler JD, Anderson JE. Reliability limits of the modified Thomas test for assessing rectus femoris muscle flexibility about the knee joint. J Athl Train. 2008;43(5):470-476. PubMed ID: 18833309 doi:10. 4085/1062-6050-43.5.470

8. Vigotsky AD, Lehman GJ, Beardsley C, Contreras B, Chung B, Feser EH. The modified Thomas test is not a valid measure of hip extension unless pelvic tilt is controlled. PeerJ. 2016;4:e2325. PubMed ID: 27602291 doi:10.7717/peerj.2325

9. Aefsky B, Fleet N, Myers H, Butler RJ. Reliability and validity of a novel approach to measure hip rotation. J Sport Rehabil. 2016; 25(4):330-337. PubMed ID: 27632825 doi:10.1123/jsr.2015-0013

10. Gradoz MC, Bauer LE, Grindstaff TL, Bagwell JJ. Reliability of hip rotation range of motion in supine and seated positions [published online ahead of print July 16, 2018]. J Sport Rehabil. 2018;27(4). 1-4. doi:10.1123/jsr.2017-0243 